\title{
Proposta de planejamento estratégico para melhorias na gestão de um Núcleo de Inovação Tecnológica (NIT)
}

Ingrid Zanuto de Freitas

Mestranda no Programa de Pós-Graduação em Administração - Mestrado Profissional da Universidade Estadual do Oeste do Paraná

ingrid_zanutodefreitas@ hotmail.com

https://orcid.org/0000-0001-9274-6544

Sandra Mara Stocker Lago

Doutora em Desenvolvimento Regional e Agronegócio pela Universidade Estadual do Oeste do Paraná. Professora no Programa de Pós-Graduação em Administração - Mestrado Profissional da Universidade Estadual do Oeste do Paraná

smstocker@uol.com.br

https://orcid.org/0000-0001-7452-9853

Ronaldo Bulhões

Doutor em Economia Aplicada pela Universidade Estadual de Campinas.

Professor no Programa de Pós-Graduação em Administração - Mestrado Profissional da Universidade Estadual do Oeste do Paraná

ronaldo@melros.com.br

https://orcid.org/0000-0002-1378-5308

\section{Editor Científico: José Edson Lara}

Organização Comitê Científico

Double Blind Review pelo SEER/OJS

Recebido em 26.08.2019

Aprovado em 05.12.2019

Este trabalho foi licenciado com uma Licença Creative Commons - Atribuição - Não Comercial 3.0 Brasil 


\title{
Resumo
}

Objetivo: Analisar o atual cenário e propor um planejamento estratégico para o Núcleo de Inovação Tecnológica (NIT) da Universidade Estadual do Oeste do Paraná (UNIOESTE), com vistas a aprimorar a gestão interna do mesmo.

Metodologia/abordagem: Por meio de observação participante, pesquisa documental e entrevistas com o gestor e demais colaboradores, foram elaborados o Canvas, a análise SWOT assim como a missão, visão e objetivos do NIT.

Originalidade/Relevância: Percebe-se que os NITs enfrentam diversos problemas e dificuldades que advêm do governo, das ICTs e do próprio NIT, e, assim, que há fatores que não podem ser controlados pelos NITs, mas que há fatores que advêm de problemas internos do próprio NIT e que podem ser amenizados ou melhorados com o aprimoramento da gestão desses departamentos, dando clareza quanto à direção e controle das suas atividades, utilizandose da aplicação prática de ferramentas estratégicas.

Principais resultados: Foram elaboradas as estratégias, metas e indicadores de desempenho, que tiveram como característica comum o objetivo de minimizar os pontos fracos do departamento e suas ameaças e potencializar seus pontos fortes e suas oportunidades.

Contribuições teóricas/metodológicas: Ressalta-se que o resultado deste estudo pode servir como base e ser adaptado em outros NITs nacionais e internacionais, visto as dificuldades semelhantes enfrentadas por estes departamentos.

Contribuições sociais/para a gestão: Como contribuição ao NIT objeto da pesquisa e a outros NITs, têm-se a posse de um instrumento de planejamento e monitoramento que pode ser adaptado para subsidiar suas atividades de forma eficiente e sustentável.

Palavras-chave: Núcleo de Inovação Tecnológica; Gestão; Ferramentas estratégicas.

\section{Proposal of strategic planning for improvements in the management of a Technological Innovation Center (TIC)}

\begin{abstract}
Study: Analyze the current scenario and propose a strategic planning for the Technological Innovation Center (TIC) of the State University of the West of Paraná (UNIOESTE), in order to improve the internal management of the department.

Methodology/approach: Through participant observation, documentary research and interviews with the manager and other collaborators, were prepared the Canvas, SWOT analysis and the mission, vision and objectives of the TIC.

Originality/Relevance: It is clear that TICs face a number of problems and difficulties arising from government, STIs and the TIC itself, and, thus, there are factors that cannot be controlled by TICs, but there are factors that arise from internal problems within the TIC itself and can be mitigated or improved by improving the management of these departments, providing clarity on the direction and control of their activities, using the practical application of strategic tools. Main results: The strategies, goals and performance indicators were elaborated, with the common characteristic of minimizing the weaknesses of the department and its threats and enhancing its strengths and opportunities.

Theoretical/methodological contributions: It is noteworthy that the result of this study can serve as a basis and be adapted to other national and international TICs, given the similar difficulties faced by these departments.
\end{abstract}


Social contributions/to management: As a contribution to the research object TIC and other TICs, have up a planning and monitoring instrument that can be adapted to subsidize their activities in an efficient and sustainable manner.

Keywords: Technological Innovation Center; Management; Strategic tools.

\section{Propuesta de planificación estratégica para mejoras en la gestión de un Núcleo de Innovación Tecnológica (NIT)}

\section{Resumen}

Objetivo: Analizar el actual escenario y proponer una planificación estratégica para el Núcleo de Innovación Tecnológica (NIT) de la Universidad Estadual del Oeste de Paraná (UNIOESTE), para mejorar la gestión interna del departamento.

Metodología/enfoque: Por medio de observación participante, investigaciones en documentos y entrevistas con el gestor y demás colaboradores, se elaboraron el Canvas, el análisis SWOT así como la misión, visión y objetivos del NIT.

Originalidad/Relevancia: Está claro que los NITs enfrentan una serie de problemas y dificultades que surgen del gobierno, las ICTs y el propio NIT, y, por lo tanto, hay factores que no pueden ser controlados por los NITs, pero existen factores que surgen de problemas internos dentro del NIT y pueden mitigarse o mejorarse mejorando la gestión de estos departamentos, proporcionando claridad sobre la dirección y el control de sus actividades, utilizando la aplicación práctica de herramientas estratégicas.

Principales resultados: Se elaboraron las estrategias, metas e indicadores de desempeño, que tuvieron como característica común el objetivo de minimizar los puntos débiles del departamento y sus amenazas y potenciar sus puntos fuertes y sus oportunidades.

Contribuciones teóricas/metodológicas: Cabe destacar que el resultado de este estudio puede servir de base y adaptarse a otros NITs nacionales e internacionales, dadas las dificultades similares que enfrentan estos departamentos.

Contribuciones sociales/a la gestión: Como contribución al NIT de investigación y otros NITs, tenemos un instrumento de planificación y monitoreo que puede adaptarse para subsidiar sus actividades de manera eficiente y sostenible.

Palabras clave: Núcleo de Innovación Tecnológica; Gestión; Herramientas estratégicas.

\section{Introdução}

A inovação tecnológica se tornou essencial, considerando a necessidade dos países se desenvolverem no âmbito econômico e social e, assim, se tornarem mais competitivos (Figueiredo, 2005; Almeida et al., 2014; Silva \& Silva, 2015).

A capacidade de gerar inovações está intrinsicamente relacionada à interação entre o setor acadêmico, o setor produtivo e o setor público (Zandavalli et al., 2016). Nesse contexto, as universidades se destacam como de extrema importância (Pereira et al., 2009), e passaram a 
ter uma nova missão além da produção de conhecimento, que é a de contribuir com o desenvolvimento econômico e social do país por meio da transferência desses conhecimentos, conhecida como transferência de tecnologia, para o setor produtivo (Rennó et al., 2016; Beltrán et al., 2017; Mikosz \& Lima, 2018; Queiroz \& Meza, 2018).

No Brasil, essa interação entre os setores acadêmico, público e privado para alavancar a competitividade do país por meio da promoção das inovações foi regulamentada com a aprovação da Lei 10.973 ou Lei de Inovação em 2004, a qual impôs, a partir de então, que as Instituições Científicas, Tecnológicas e de Inovação (ICTs) devem ter órgãos internos para, dentre outras coisas, gerir suas políticas de inovação, propriedade intelectual e transferências de tecnologia, denominados Núcleos de Inovação Tecnológica - NITs (Iata et al., 2017; Lata \& Cunha, 2018). Portanto, o bom estabelecimento, estruturação e funcionamento dos NITs é de extrema importância, já que eles podem ser atores de mudança dentro das ICTs e facilitadores para a divulgação de pesquisas e formação de parcerias, principalmente com o setor produtivo (Paranhos et al., 2018).

Os NITs têm demandas tanto da parte interna da universidade quanto da parte externa onde ocorre a comercialização das pesquisas, as quais são inerentes ao seu relacionamento de múltiplas relações e que muitas vezes se tornam conflitantes. Para administrar tais conflitos é necessária uma gestão peculiar tanto com acadêmicos quanto com administradores, comunidade e governo com vistas a ter êxito em sua atuação (O'Kane et al., 2015; Silva, 2015; Sartori et al., 2017).

Neste sentido, a organização e a gestão são primordiais para o desempenho assim como para os resultados de um NIT (Silva et al., 2015). Portanto, o estudo dos NITs e de seus processos administrativos assim como a compreensão da efetividade das suas ações gerenciais é de extrema importância (Costa \& Junior, 2016), mostrando as oportunidades para o aprimoramento constante das suas práticas e processos de gestão (Souza, 2011; Pietrovski, 2017).

Para se ter uma gestão eficiente, entre outros, necessita-se de um planejamento estratégico com vistas a identificar os pontos fortes e fracos de uma organização, assim como, conhece-la melhor. Dentre as ferramentas para realização de planejamento estratégico destacam-se a análise SWOT (Strengths, Weaknesses, Opportunities e Threats) e o Business Model Canvas.

Diante desse cenário, é de extrema importância, como retratado por Bakouros e Samara (2010), Garcia et al. (2017) e Katz et al. (2018), a elaboração da análise SWOT e seu exercício 
constante nos NITs, e, ainda, a formulação de um planejamento estratégico, decorrente da análise SWOT. É importante, ainda, a utilização do Business Model Canvas, como retratado por Marin et al. (2017), para reunir todas as informações necessárias e ser possível trabalhar com os diversos cenários das atividades desses departamentos, assim como a utilização de indicadores de desempenho, que podem permitir ao NIT e, consequentemente, à universidade, entender, avaliar e acompanhar a evolução dos seus processos e atividades, e, assim, promover e estimular a interação e cooperação com o setor produtivo e com a sociedade (Bueno \& Torkimian, 2018).

Nesse contexto, o objetivo deste estudo foi analisar o atual cenário e propor um planejamento estratégico para o Núcleo de Inovação Tecnológica (NIT) da Universidade Estadual do Oeste do Paraná (UNIOESTE), com vistas a aprimorar a gestão interna do mesmo. Assim, este relato descreve como a aplicação prática de ferramentas estratégicas nos Núcleos de Inovação Tecnológica é essencial para os gestores e colaboradores e pode proporcionar ganhos em desempenho de forma eficiente e eficaz.

\section{Referencial Teórico}

\subsection{Núcleos de Inovação Tecnológica}

Conforme Ustundag et al. (2011), para as instituições conseguirem transferir seus conhecimentos para o setor produtivo e para a sociedade de maneira formal, necessitam de Escritórios de Transferência de Tecnologia (ETTs), os quais são de extrema importância para a proteção e comercialização da propriedade intelectual dessas instituições. No Brasil, os NITs foram criados com o propósito de desempenhar a mesma função dos ETTs - retratados na literatura internacional (Coelho \& Dias, 2016; Paranhos et al., 2018).

Portanto, considerando que as atividades dessa nova missão das instituições se tornaram parte integrante principalmente das universidades, é crucial, tanto do ponto de vista acadêmico quanto profissional, a compreensão do contexto no qual elas são realizadas (Sengupta \& Ray, 2017).

De acordo com a Lei $n^{\circ}$ 10.973/2004, o Núcleo de Inovação Tecnológica (NIT), corresponde a uma "estrutura instituída por uma ou mais ICTs, com ou sem personalidade jurídica própria, que tenha por finalidade a gestão de política institucional de inovação e por 
competências mínimas as atribuições previstas nesta Lei (Redação pela Lei n 13.243, de 2016)" (Lei no 10.973, 2004, Art. 2).

A tendência é que algumas atribuições dos NITs desapareçam ou tornem-se secundárias enquanto outras, como a elaboração de estudos necessários para o planejamento estratégico e a prospecção tecnológica, ocupem uma posição central (Alves et al., 2015). Portanto, para um melhor desempenho dos escritórios de transferência de tecnologia brasileiros, de acordo com Fujino e Stal (2007, p. 117), é preciso "redefinir as estruturas administrativas e operacionais, no sentido de torná-las mais ágeis e aptas a operar no contexto da parceria com a empresa".

Pode-se verificar que os NITs enfrentam diversos problemas que advêm do governo ou das ICTs em que estão inseridos, conforme observa-se na pesquisa de Teixeira (2018), a qual apontou que a maioria dos NITs não têm orçamento próprio e não se tem cargos criados nas ICTs para estes departamentos e na pesquisa de Mikosz e Lima (2018), a qual analisou o NIT de uma universidade federal, e constatou que entre as principais dificuldades dos NITs está a burocracia interna da universidade.

Porém, observa-se, também, que há problemas enfrentados que advêm do próprio NIT, como afirmado na pesquisa de Beltrán et al. (2017), em uma análise do alinhamento das atividades realizadas pelo Escritório de Transferência de Tecnologia (ETT) de uma universidade espanhola com os objetivos da universidade, em qual constataram que os gerentes e os colaboradores do ETT desenvolvem suas atividades diariamente, sem levar em consideração seu grau de contribuição ou suas implicações para as metas da instituição, e assim podem prejudicar essa nova missão da universidade.

As pesquisas de Desidério e Zilber (2014), Machado et al. (2017) e Rosa e Frega (2017), que analisaram NITs do Brasil, constataram que esses órgãos precisam incentivar os pesquisadores na busca dos NITs, pois há dificuldades no conhecimento, compreensão e clareza do papel desses departamentos até mesmo no âmbito da comunidade acadêmica interna das instituições em que estão inseridos. Silva et al. (2015), por meio do diagnóstico de NITs de universidades públicas do estado do Paraná, constatou que os NITs não possuem um sistema estruturado para condução dos processos em suas atividades e têm dificuldades para estabelecer relacionamentos internos entre seus membros e outros pesquisadores da universidade, o que acarreta em dificuldades para desenvolver pontos externos como novos relacionamentos com pesquisadores e setor produtivo.

A pesquisa de Bortolini et al. (2014), diagnosticou os NITs brasileiros e constatou que a maioria dos NITs não possui nenhum tipo ou método que vise incentivar a transmissão dos 
conhecimentos adquiridos pelos atuais ocupantes dos cargos, não registra as suas relações com empresas, não promove eventos em conjunto com empresas e não utiliza ferramentas de auxílio à gestão interna.

Percebe-se, assim, que a Lei está sendo cumprida pelas ICTs ao criarem seus NITs, porém, as dificuldades para estes departamentos executarem suas principais funções ainda são enormes (Paranhos et al., 2018). Portanto, é importante compreender as principais dificuldades que os NITs enfrentam no cumprimento de suas atividades, compreendendo, então, suas gestões (Bortolini et al., 2014), considerando que há fatores que não podem ser controlados pelos NITs, como os problemas que advêm do governo ou das ICTs, mas que há fatores que advêm de problemas internos do próprio NIT, e, assim, podem ser amenizados ou melhorados com o aprimoramento da gestão desses departamentos, dando clareza quanto à direção e controle das suas atividades, utilizando-se da aplicação prática de ferramentas estratégicas.

\subsection{Aplicação de ferramentas estratégicas nos Núcleos de Inovação Tecnológica}

Segundo Weckowska (2015), a orientação estratégica é importante para o desenvolvimento em ETTs, em quais há várias relações e ocorrem diversas transações, principalmente pela prática de comercialização. As medidas utilizadas para avaliar o desempenho de um ETT precisam abranger os seus colaboradores, a comunidade acadêmica e as políticas e estratégias de propriedade intelectual da instituição, e podem ser influenciadas pelo modelo operacional do escritório, podendo ser quantitativas ou qualitativas (Gumbi, 2010).

A pesquisa de Sharifi et al. (2014) buscou verificar a percepção dos gerentes de Escritórios de Transferência de Conhecimento de universidades do Reino Unido e concluiu que é necessário que esses escritórios desenvolvam processos adequados para gerenciar os diversos relacionamentos, mecanismos de troca de tecnologia e contratos; para aplicar práticas gerenciais para recursos legais e humanos e para monitorar atividades; e, ainda, é necessário que contratem uma equipe capacitada.

Analisando o NIT de uma universidade estadual, Sartori et al. (2017), constataram algumas principais dificuldades como comunicação inadequada e falta de proatividade na busca por informações no mercado. Sugeriram, então, que o NIT deve utilizar instrumentos de gestão como benchmarking e best practice para identificação de oportunidades no mercado e formular um planejamento estratégico que possa dar maior compreensão de seu ambiente e promover 
maior agilidade nas respostas a ele, o direcionando para cumprimento de seu papel dentro de toda a instituição, promovendo maior impacto no desenvolvimento socioeconômico regional.

Pires e Quintella (2015), analisando o NIT de uma universidade federal, propõem algumas ações para o NIT que podem ser aplicadas em outros NITs, como mapear experiências de sucesso de outras universidades brasileiras, com estrutura similar à universidade em que o NIT está inserido; criar um regimento interno que normatiza as ações/funções do NIT junto à universidade; criar uma previsão orçamentária das demandas do NIT; e criar um planejamento estratégico que direcione o NIT para o cumprimento de seus objetivos.

Analisando os Escritórios de Transferência de Tecnologia de uma rede de universidades romena, Marin et al. (2017) utilizaram o Business Model Canvas para reunir todas as informações necessárias e poder trabalhar com os diversos cenários das atividades do ETT em um só espaço concentrado, considerando seu segmento de clientes, portfólio de serviços oferecidos e proposta de valor a ser alcançada, e, assim, aumentar a eficácia desses escritórios.

É importante identificar as variáveis que afetam o desempenho do Escritório de Transferência de Tecnologia e as relações entre elas (Ustundag et al., 2011), sendo assim, no trabalho de Garcia et al. (2017) foi estudado o NIT de uma universidade federal, a fim de verificar suas variáveis internas e externas, e, como ferramenta, foi utilizada a análise SWOT, que identificou os pontos fortes e fracos e as oportunidades e ameaças, e, assim, foi analisada a gestão do NIT. Os autores concluem, ainda, que o NIT precisa de um planejamento estratégico, com as atividades e metas previstas para o ano.

Katz et al. (2018) utilizaram a análise SWOT para o processo de implantação e estruturação de um NIT de um Instituto de Pesquisa, a fim de planejar suas futuras ações, que foram incluídas em um planejamento estratégico. Os autores apontam, ainda, que o NIT criará indicadores para mensuração de resultados e desempenho, para aprimorar o processo de gestão do departamento. O estudo de Bakouros e Samara (2010) analisou os Escritórios de Ligação Acadêmica e as Unidades de Transferência de Tecnologia da Grécia, sendo que os autores elaboraram uma análise SWOT, afirmando que a exploração do ambiente interno e externo é uma parte importante para o processo de planejamento estratégico. Com base na análise SWOT, os autores montaram um planejamento estratégico com objetivos e ações para cada objetivo.

A prática do NIT em realizar um planejamento estratégico anual, segundo Pereira et al. (2017), encaminha soluções para diversas situações problemáticas, evitando conflitos de maior dimensão. Por meio do estudo de um NIT de uma universidade federal, Santos e Silva (2017) propõem que seja elaborado um planejamento estratégico junto a um mapa estratégico, com 
objetivos e ações estratégicas do núcleo; e um sistema de monitoramento de indicadores, associados aos objetivos e metas definidas.

Quanto aos índices e indicadores de desempenho, Bueno e Torkimian (2018) afirmam que nos NITs, permitem uma avaliação da efetividade das ações realizadas e contribuem na definição ou redefinição de estratégias.

\section{Metodologia}

Esta pesquisa possui abordagem qualitativa e corresponde a um estudo de caso, que, conforme Yin (2015), é a investigação em profundidade de um determinado fenômeno em seu contexto.

O presente estudo, na forma de relato técnico, retrata a intervenção realizada no NIT da UNIOESTE, localizado em Cascavel-PR. A intervenção aplicada na solução da situaçãoproblema identificada decorreu da consultoria desenvolvida no departamento.

A coleta de dados foi realizada a partir de pesquisa bibliográfica com o levantamento do contexto dos NITs e de trabalhos sobre os temas pertinentes à sustentação científica da consultoria e posteriormente da intervenção, sendo observadas, também, as Leis nacionais pertinentes aos NITs; a partir da pesquisa em documentos internos do NIT, em que foram analisados memorandos, ofícios, portarias, e-mails, relatórios de atividades, regulamentos e resoluções do NIT e da universidade; e, ainda, a partir de observação participante, já que a consultora possui uma bolsa para atuar no NIT objeto do estudo, o que permitiu a participação ativa da pesquisadora.

A coleta de dados desenvolveu-se, também, por meio de reuniões periódicas com o gestor e demais colaboradores do departamento, totalizando seis reuniões, em quais foram realizadas entrevistas semiestruturadas. A primeira reunião foi realizada no dia 18 de março de 2019, com o coordenador do NIT, em qual foi identificada a principal necessidade do departamento, que, de acordo com o gestor, é saber onde o NIT está e onde ele quer chegar; e a segunda reunião ocorreu no dia 25 de março de 2019, dessa vez com os colaboradores do NIT, a fim de explicar sobre a consultoria e de confirmar a necessidade do setor.

As demais reuniões foram realizadas em conjunto com o coordenador do NIT e com todos os colaboradores, no dia 15 de abril de 2019, com foco no levantamento de informações para a elaboração do Canvas e da análise SWOT do departamento; e no dia 03 de maio de 2019, 
com foco no levantamento de informações para a elaboração da missão, da visão e dos objetivos estratégicos do NIT. A partir das informações levantadas, no dia 14 de maio de 2019 foi feita uma reunião com o gestor para a apresentação das propostas de estratégias, metas e indicadores de desempenho para o NIT, e, assim, com as adaptações propostas por ele, no dia 28 de maio de 2019 foi apresentada a concretização final das propostas para o gestor e para todos os colaboradores do departamento.

\section{Contexto da Organização e da Situação-problema}

O Núcleo de Inovações Tecnológicas (NIT) da UNIOESTE, objeto deste estudo, foi criado em 1992, está situado na Reitoria da universidade, em Cascavel-PR, e é vinculado à PróReitoria de Pesquisa e Pós-Graduação - PRPPG (NIT, 2019).

A estrutura do NIT abrange um Conselho Técnico-Científico (CTC), do qual participam representantes de todos os campi, além do coordenador geral do NIT e um representante da PRPPG; uma Coordenadoria Geral; e quatro divisões, que correspondem a Divisão de Projetos Tecnológicos (DPT), Divisão de Propriedade Intelectual (DPI), Divisão de Incubadora de Empresas (DIE) e Divisão de Informação Tecnológica (DIT) (NIT, 2019).

O NIT atualmente é formado por um coordenador geral, o qual já era servidor da universidade e foi realocado para o NIT em 01/09/2018; um servidor da universidade realocado para o NIT e que está neste departamento desde 23/01/2019; dois bolsistas, que estão no departamento desde 01/10/2018 e 09/10/2018 (sendo que esta última é consultora desta presente intervenção); e um estagiário, que está no departamento desde abril de 2018.

O caráter temporário da maioria dos funcionários do NIT se liga ao fato da dificuldade na gestão do conhecimento deste setor, principalmente quando não há o registro dos aprendizados pelos colaboradores, conforme citado por Santos e Silva (2017), e, assim, não há a transmissão dos conhecimentos adquiridos pelos atuais ocupantes dos cargos (Bortolini et al., 2014), fato que, inclusive, foi e ainda continua sendo uma das maiores dificuldades para a consultora desta presente intervenção no desenvolvimento dos trabalhos como bolsista do NIT em estudo, pois não houve nenhum tipo de treinamento para as atividades técnicas, o que se somou ao fato de ter entrado no departamento na mesma época do outro bolsista, considerando que ambos nunca tinham tido experiência com propriedade intelectual e/ou transferência de tecnologia antes. 
Constatou-se que as quatro divisões do NIT instituídas em seu regulamento não são definidas dentro do departamento, sendo que das quatro, só uma possui um funcionário atual no cargo de chefia, e que as outras três divisões não possuem ninguém como responsável atualmente. Pôde-se constatar, ainda, que os papéis de algumas divisões não estão sendo desempenhados, como é o caso da Divisão de Incubadora de Empresas, e, ainda, que os papéis das outras três divisões estão sendo desempenhados de maneira sobreposta e não sistemática. Ressalta-se que, na pesquisa bibliográfica, foi levantado o estudo de Bakouros e Samara (2010), em qual foi encontrado como um ponto fraco a sobreposição de papéis das pessoas que trabalham nos NITs.

Foi constatado que os arquivos digitais e físicos que possuem informações sobre as patentes, softwares e marcas assim como sobre as transferências/fornecimentos de tecnologia realizadas, as quais são as principais atividades do NIT, são arquivos soltos, desconexos e desatualizados, que não permitem ter informações precisas e de fácil acesso, sendo que foi necessário pesquisar direto na base do INPI pois o próprio NIT não tem suas patentes de forma atualizada e organizada. Essa observação vem de encontro aos achados, na literatura utilizada, de que o mapeamento, organização e classificação das patentes de um NIT ajuda a identificar as áreas onde a universidade tem mais atuação, e, ainda, a perceber suas vantagens competitivas em termos de oferta e transferência de tecnologia. Vem de encontro, especificamente, também, ao estudo de Bortolini et al. (2014), que diagnosticou os NITs brasileiros e constatou que a maioria dos NITs não registra as suas relações com empresas.

Nas buscas, foram observadas diversas informações desatualizadas no site do NIT. Conforme descrição da Divisão de Informação Tecnológica no regulamento geral do NIT, está indicado que cabe a esta divisão manter atualizada a página do NIT. Portanto, confirma-se que algumas funções estão sobrepostas entre as divisões, e, ainda, que algumas funções não estão sendo desempenhadas.

Pôde-se constatar, ainda, que há um manual para procedimentos de inovação na UNIOESTE elaborado em 2012, disponibilizado no site do NIT, que não é atualizado desde essa época; que há formulários para solicitação de registros de patente, softwares e marcas, disponibilizados no site do NIT, que também não são revisados há anos; e que os regulamentos internos da universidade não foram atualizados após a alteração da Lei de Inovação em 2016.

Quanto ao controle de suas entradas e saídas de caixa, constatou-se que o NIT não tem esse controle. O ponto principal é quanto as receitas resultantes das transferências de tecnologia 
por meio de contratos e convênios com empresas, denominadas royalties, que não são acompanhadas. Mesmo que o setor financeiro da universidade seja responsável por receber essas entradas de caixa, é responsabilidade do NIT acompanhar e controlar com a finalidade de saber se todas as empresas estão pagando os royalties devidos ao NIT e à universidade.

Por último, foi constatado que as finalidades, ou seja, os objetivos do NIT, diferem entre as informações do seu site e dos seus relatórios anuais de atividades. Portanto, é necessário definir esses objetivos e verificar se estão de acordo com as finalidades do NIT expressas no regulamento da universidade, e, ainda, com as competências mínimas exigidas na nova Lei 13.246/16. Observa-se, ainda, que a definição de quais realmente são os objetivos do NIT, é necessária para definir as estratégias, metas e indicadores de desempenho do departamento, por meio de um planejamento estratégico.

Com base na pesquisa bibliográfica, na pesquisa em documentos internos do NIT e na observação participante no NIT objeto do estudo, foram identificados diversos problemas no departamento que interferem no seu desempenho, sendo que a maioria decorre da deficiência da sua gestão interna, que pode ser aprimorada utilizando-se da aplicação prática de ferramentas estratégicas, dando clareza quanto à direção e controle das suas atividades.

\section{Proposta de Intervenção}

Por meio do levantamento dos estudos sobre o contexto dos NITs; da pesquisa em documentos internos e da observação participante no NIT objeto de estudo; e das reuniões e entrevistas com o gestor e demais colaboradores do departamento, foi elaborado, então, primeiramente, o Canvas do NIT, o qual pode ser observado na Figura 1. Segundo Osterwalder e Pigneur (2011), o Canvas é composto por nove componentes, que abrangem os segmentos de clientes atendidos pela organização, a proposta de valor oferecida a esses segmentos de clientes, os canais para oferecer essa proposta de valor aos seus segmentos de clientes, as formas da organização se relacionar com seus segmentos de clientes, as fontes de receita da organização resultantes da entrega da sua proposta de valor, os recursos principais utilizados pela organização para entregar sua proposta de valor aos clientes, as principais atividades desenvolvidas pela organização para entregar sua proposta de valor, as parcerias chave da organização para operar e gerar receita e os custos de operação da organização. 


\begin{tabular}{|c|c|c|}
\hline \multicolumn{3}{|c|}{ CANVAS } \\
\hline Componente & Pilar conceitual & Itens definidos \\
\hline Segmento de clientes & Entrega de valor & $\begin{array}{l}\text { Comunidade acadêmica } \\
\text { universidade; Empresários }\end{array}$ \\
\hline Proposta de valor & Criação de valor & $\begin{array}{l}\text { Serviço gratuito a proteção das invenções da } \\
\text { comunidade acadêmica da universidade; } \\
\text { Suporte a inovação dentro da universidade; } \\
\text { Intermediação da universidade com o } \\
\text { mercado }\end{array}$ \\
\hline Canais & Entrega de valor & $\begin{array}{l}\text { Site; Facebook, Eventos em parceria; } \\
\text { Prospecção de empresas; Grupo de Trabalho } \\
\text { (GT) }\end{array}$ \\
\hline Relacionamento com clientes & Entrega de valor & Atendimento a cada demanda \\
\hline Fontes de receita & Captura de valor & $\begin{array}{l}\text { Eventos; Patrocínios; Doações da Receita } \\
\text { Federal; Royalties; Parcerias; UNIOESTE }\end{array}$ \\
\hline Recursos principais & Criação de valor & $\begin{array}{l}\text { Capital humano; Capital intelectual da } \\
\text { UNIOESTE }\end{array}$ \\
\hline Atividades principais & Criação de valor & $\begin{array}{l}\text { Prestação de serviço de avaliação de } \\
\text { possíveis pedidos de patentes, marcas e } \\
\text { programas de computador; Prestação de } \\
\text { serviço de depósito de patentes, registro de } \\
\text { marcas e programas de computador; } \\
\text { Monitoramento das criações no INPI; } \\
\text { Estabelecimento de convênios e parcerias }\end{array}$ \\
\hline Parcerias principais & Criação de valor & $\begin{array}{lcl}\text { Universidades; } \quad \text { Instituições } & \text { Bancárias; } \\
\text { Entidades empresariais; Empresas } & \end{array}$ \\
\hline Estrutura de custos & Captura de valor & $\begin{array}{llr}\text { Recursos } & \text { humanos } & \text { (bolsistas); } \\
\text { Depósito/registro e manutenção das criações } \\
\text { no INPI }\end{array}$ \\
\hline
\end{tabular}

Figura 1- Canvas do NIT objeto do estudo

Fonte: Elaborada pelos autores (2019).

Ressalta-se que alguns dos componentes retratados na Figura 1 estão de acordo com o que o NIT deve ser perante a universidade e a sociedade porém distantes da realidade atual do departamento, cujas análises posteriormente foram incluídas na análise SWOT elaborada.

No componente que trata do segmento de clientes, no qual o NIT busca atingir a comunidade acadêmica interna da universidade e os empresários, observou-se certo distanciamento do primeiro grupo (comunidade acadêmica interna da universidade) pois não há ações efetivas para atrair essa comunidade acadêmica ao NIT, principalmente se tratando da comunidade acadêmica dos outros campi da universidade.

No item que trata da proposta de valor do NIT, observa-se que a ação mais entregue aos clientes é a de serviço gratuito a proteção das invenções da comunidade acadêmica da universidade, quando solicitadas ao NIT. Portanto, como relatado anteriormente, para um suporte a inovação dentro da universidade faltam ações efetivas para o NIT atuar com mais representatividade, e, ainda, quanto a intermediação da universidade com o mercado, observase que há várias ações do NIT quanto à novas parcerias, porém, há falta de ações efetivas para 
"vender" ao mercado a propriedade intelectual já protegida da universidade, sendo que a maioria das patentes e softwares já protegidos pelo NIT estão apenas gerando custo de manutenção para a universidade, a qual não está tendo nenhum retorno financeiro.

Outra discrepância é encontrada no terceiro item, que trata dos canais utilizados para oferecer a proposta de valor aos clientes, no qual o site do NIT é mencionado, porém observouse que este meio de comunicação não é atualizado. Quanto aos eventos em parceria, como relatado anteriormente, percebe-se várias ações do NIT com eventos em parceria com empresas, porém falta uma parceria mais efetiva com outros departamentos da própria universidade, e, ainda, faltam eventos em parceria com empresas focados nas áreas específicas em que o NIT necessita, como para "vender" a propriedade intelectual parada, como relatado anteriormente, o que vem de encontro a prospecção de empresas definidas nesse item, a qual na realidade não está focada e restrita como deveria.

Quanto às fontes de receita, percebe-se que há entradas advindas de todos os itens definidos, porém, que não há o controle, pelo NIT, de nenhuma dessas entradas. O ponto principal é na questão dos royalties, os quais correspondem aos valores que as empresas pagam ao NIT e a universidade pelo uso da propriedade intelectual da universidade que já foi transferida ao mercado, e que não são acompanhados, ou seja, não há o controle e garantia de que todas as transferências de tecnologia já efetuadas estão gerando retorno, sendo que as empresas podem não estar pagando ou não estar pagando a quantia que foi estabelecida em contrato.

Quanto às atividades principais do NIT, observou-se que, para o primeiro item definido, esse processo instituído para avaliação dos pedidos de proteção que chegam ao NIT, na realidade se concentra somente nos pedidos de patentes, cuja avaliação sempre é feita por professores da área do pedido de patente, os quais, por meio de convite feito pelo NIT e de forma voluntária, atuam como pareceristas desses pedidos. Observa-se que falta por parte do NIT uma análise mais crítica em relação a esses pedidos de proteção que chegam até o departamento, considerando previamente a possibilidade desse produto/serviço atingir o mercado.

No último item, que é a estrutura de custos, observa-se que assim como suas entradas de caixa, como relatado anteriormente, o NIT também não tem controle próprio das suas saídas de caixa. Mesmo os principais custos do departamento sendo pagos por agências de fomento e pela universidade, é essencial que o controle de suas entradas e saídas para a sua sustentabilidade financeira. 
Posteriormente, foi elaborada a análise SWOT do NIT em estudo, a qual está expressa na Figura 2. A análise SWOT (Strengths, Weaknesses, Opportunities e Threats), segundo Dyson (2004), permite identificar os pontos fortes e fracos (Strengths e Weaknesses) de uma organização e as oportunidades e ameaças (Opportunities e Threats) no ambiente, assim como, posteriormente, desenvolver estratégias para aproveitar os pontos fortes, eliminar as fraquezas, explorar as oportunidades e combater as ameaças.

Conforme observa-se na Figura 2, a aplicação da análise SWOT permitiu identificar os quatro quadrantes que envolvem as atividades do NIT, mostrando que é de extrema importância a elaboração de um planejamento estratégico para o departamento a fim de minimizar seus pontos fracos e suas ameaças e potencializar seus pontos fortes para alcance das suas oportunidades.

Alguns pontos que merecem destaque nos pontos fortes é em relação à participação do NIT em grupos nacionais como o FORTEC (Fórum Nacional de Gestores de Inovação e Transferência de Tecnologia) e o grupo técnico de empreendedorismo do SEBRAE (Serviço Brasileiro de Apoio às Micro e Pequenas Empresas), em grupos regionais como o SRI (Sistema Regional de Inovação Oeste do Paraná) e em grupos locais como o Iguassu Valley da ACIC (Associação Comercial e Industrial de Cascavel).

Quanto aos pontos fracos, ressalta-se a dependência econômica e administrativa da universidade, pois a dependência econômica abre oportunidades para o NIT alavancar seu dinheiro em caixa angariando recursos com outras fontes de receitas como eventos com parceiros de dentro e fora da universidade e royalties com a "venda" da propriedade intelectual (transferência de tecnologia), já que os principais custos do departamento são pagos por agências de fomento (salários dos bolsistas) e pela universidade (salários dos demais funcionários, depósitos/registros e manutenção das criações no INPI etc.). Assim, o NIT tem um suporte inicial para alavancar seu dinheiro em caixa até atingir sua sustentabilidade financeira e não depender mais dos recursos da universidade, o que pode minimizar sua dependência da mesma, garantindo maior liberdade para executar suas ações. 


\section{SWOT}

\section{PONTOS FORTES}

- Infraestrutura adequada para funcionamento do NIT;

- Participação do NIT no FORTEC, SRI, grupo técnico de empreendedorismo (SEBRAE) e Iguassu Valley (AClC);

- Número considerável de cartas-patente concedidas pelo INPI;

- Processo instituído para avaliação e seleção de patentes submetidas ao NIT;

- Número considerável de transferências de tecnologia já efetuadas.

\section{PONTOS FRACOS}

- Dependência econômica e administrativa da universidade;

- Sobreposição de tarefas dentro do departamento;

- Tarefas de divisões do NIT que não estão sendo desempenhadas;

- Desorganização dos arquivos físicos e digitais do setor;

- Falta de padronização de várias atividades e processos que o NIT realiza;

- Falta de controle das entradas e saídas de caixa por parte do NIT;

- Site do NIT não está sendo atualizado como deveria;

- Manuais e formulários disponibilizados pelo NIT estão desatualizados há anos;

- Regulamentos da universidade e do NIT não foram atualizados após a alteração da Lei de Inovação;

- Falta de pessoal fixo no departamento;

- Dificuldade na transmissão do conhecimento dos atuais ocupantes dos cargos para os próximos ocupantes:

- Falta de experiência, qualificação e domínio técnico da equipe do NIT nas áreas de inovação, propriedade intelectual e transferência de tecnologia;

- Falta de análise crítica às patentes por parte do NIT;

- Falta do uso de ferramentas estratégicas.

Figura 2 continua na próxima página... 


\section{OPORTUNIDADES}

- Grande capital intelectual da UNIOESTE;

- Bom posicionamento da UNIOESTE em rankings nacionais e internacionais;

- Bom posicionamento da UNIOESTE na área de inovação;

- Organizar as patentes do NIT para identificar as áreas em que a universidade tem mais atuação e vantagem de transferência de tecnologia;

- Organizar eventos (workshops) para empresas a fim de transferir a propriedade intelectual parada, considerando as áreas específicas das mesmas;

- Instituir processo para monitoramento dos projetos de pesquisa em andamento na universidade a fim de identificar projetos com potencial inovador;

- Desenvolver ou adquirir software para monitoramento das criações no INPI;

- Engajar alguns funcionários chave da universidade para capacitação nas áreas de propriedade intelectual e transferência de tecnologia;

- Promover ações para atuar com mais representatividade nos outros campi da universidade;

- Parcerias com outras instituições da universidade (UNI, NUPEACE, Mestrados, Doutorados, Empresas Juniores etc.) e com instituições externas (SEBRAE, AMIC, FUNDETEC, ACIC, SRI, Iguassu Valley, Iguassu-IT, PTI etc.) para viabilizar projetos, prestar serviços e captar recursos;

- Aproveitar melhor os conhecimentos específicos de cada colaborador do NIT, mesmo que não sejam em inovação, propriedade intelectual e transferência de tecnologia, para o aumento do desempenho do setor;

- Incentivar o envolvimento dos funcionários do NIT com outros NITs, a fim de buscar conhecimentos e informações que possam ser aplicados no departamento;

- Contratar terceiros para realizar os serviços técnicos do NIT.

\section{AMEAÇAS}

- Possibilidade da falta de oferta de editais de seleção de projetos pelas agências de fomento;

- Possibilidade de não aprovação de projetos enviados às agências de fomento;

- Mudança de reitor na universidade;

- Falta ou diminuição do orçamento repassado para a universidade;

- Falta de concurso público;

- Burocracia interna da universidade;

- Não recuperação da estrutura de cargos do NIT.

Figura 2- Análise SWOT do NIT objeto do estudo

Fonte: Elaborada pelos autores (2019).

Quanto às oportunidades, destaca-se o quarto, quinto e o sexto ponto, em quais a principal questão refere-se ao NIT aumentar sua proatividade. Quanto ao sétimo ponto, a oportunidade é deixar de realizar uma das suas principais e mais demoradas tarefas de forma manual, adquirindo um software que permita ao departamento ganhar eficiência e agilidade, e, quanto ao oitavo ponto, a ideia é diminuir um grande problema do NIT que é a demora nos seus processos principalmente pela falta de conhecimento da universidade nas áreas de inovação, propriedade intelectual e transferência de tecnologia, engajando funcionários chave da universidade para capacitação nessas áreas, como por exemplo um funcionário do setor de convênios, setor pelo qual passa a formalização das parcerias que o NIT realiza, um funcionário do setor jurídico, setor pelo qual também passam os convênios e contratos que o NIT realiza, dentre outros, para, assim, aumentar a agilidade e eficiência nos processos do departamento. Por fim, destaca-se o último ponto, em qual há a oportunidade de contratar terceiros para os serviços técnicos do NIT, visto a dificuldade de conseguir funcionários com conhecimento 
nessa área e principalmente funcionários fixos, e, ainda, visto a oportunidade do NIT em sair desses serviços técnicos de depósito/registro e manutenção das criações junto ao INPI para focar em atividades mais estratégicas e de prospecção.

Quanto às ameaças, destaca-se a falta ou diminuição do orçamento repassado para a universidade, que pode ser amenizada com a proatividade do NIT em angariar recursos de outras formas e controlá-los, para assim, atingir sua sustentabilidade financeira. Destaca-se, ainda, o último ponto, que é a não recuperação da estrutura de cargos do NIT, pois conforme observado e relatado pelo coordenador do setor, o NIT, há alguns anos atrás, possuía várias pessoas em seus cargos e vários projetos em andamento, sendo que hoje os cargos e a estrutura de divisões e funções continuam documentadas porém sem ninguém a frente.

Após definição e análise aprofundada do atual cenário do NIT por meio da aplicação das ferramentas estratégicas Canvas e análise SWOT, foi possível dar início à proposta de um instrumento de planejamento e monitoramento documentado e formalizado que permita aumentar o desempenho do departamento, contendo itens que se complementam, os quais são a sua missão, visão e objetivos, estratégias, metas e indicadores de desempenho. Primeiramente foram elaboradas a missão, a visão e os objetivos estratégicos do NIT, que podem ser observados na Figura 3, visto a falta, até então, dessas definições no departamento.

\section{Missão, Visão e Objetivos}

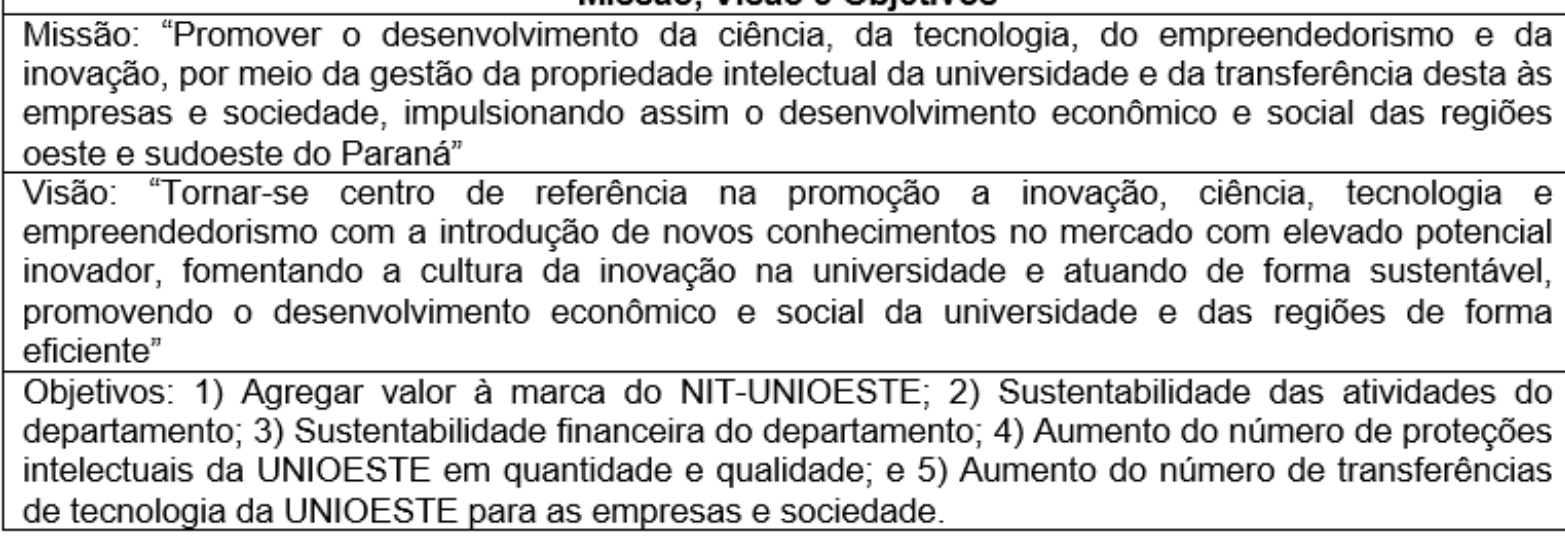

Figura 3 - Missão, visão e objetivos do NIT objeto do estudo Fonte: Elaborada pelos autores (2019).

A missão, a visão e os objetivos estratégicos do NIT, expressos na Figura 3, também foram definidos em conjunto com o coordenador do NIT e com todos os colaboradores por meio das reuniões e entrevistas, e, portanto, procuram refletir com clareza à que se propõe o NIT, buscando aprimorar o desempenho do departamento como um todo, passo inicial para ser elaborado o planejamento estratégico. 
A partir da aplicação das ferramentas Canvas e análise SWOT e da definição da missão, visão e objetivos do NIT, pôde-se propor para o departamento, então, as estratégias a serem seguidas para o alcance dos resultados de cada objetivo definido, expressas na Figura 4. Observa-se que com o planejamento estratégico, busca-se exatamente inserir a organização e sua missão no ambiente que ela atua, por meio de um processo de formulação de estratégias, relacionadas com os objetivos de médio e longo prazo da organização (Chiavenato \& Sapiro, 2003).

\begin{tabular}{|c|c|}
\hline Objetivos & Estratégias propostas \\
\hline $\begin{array}{l}\text { 1 Agregar valor à marca do } \\
\text { NIT-UNIOESTE }\end{array}$ & 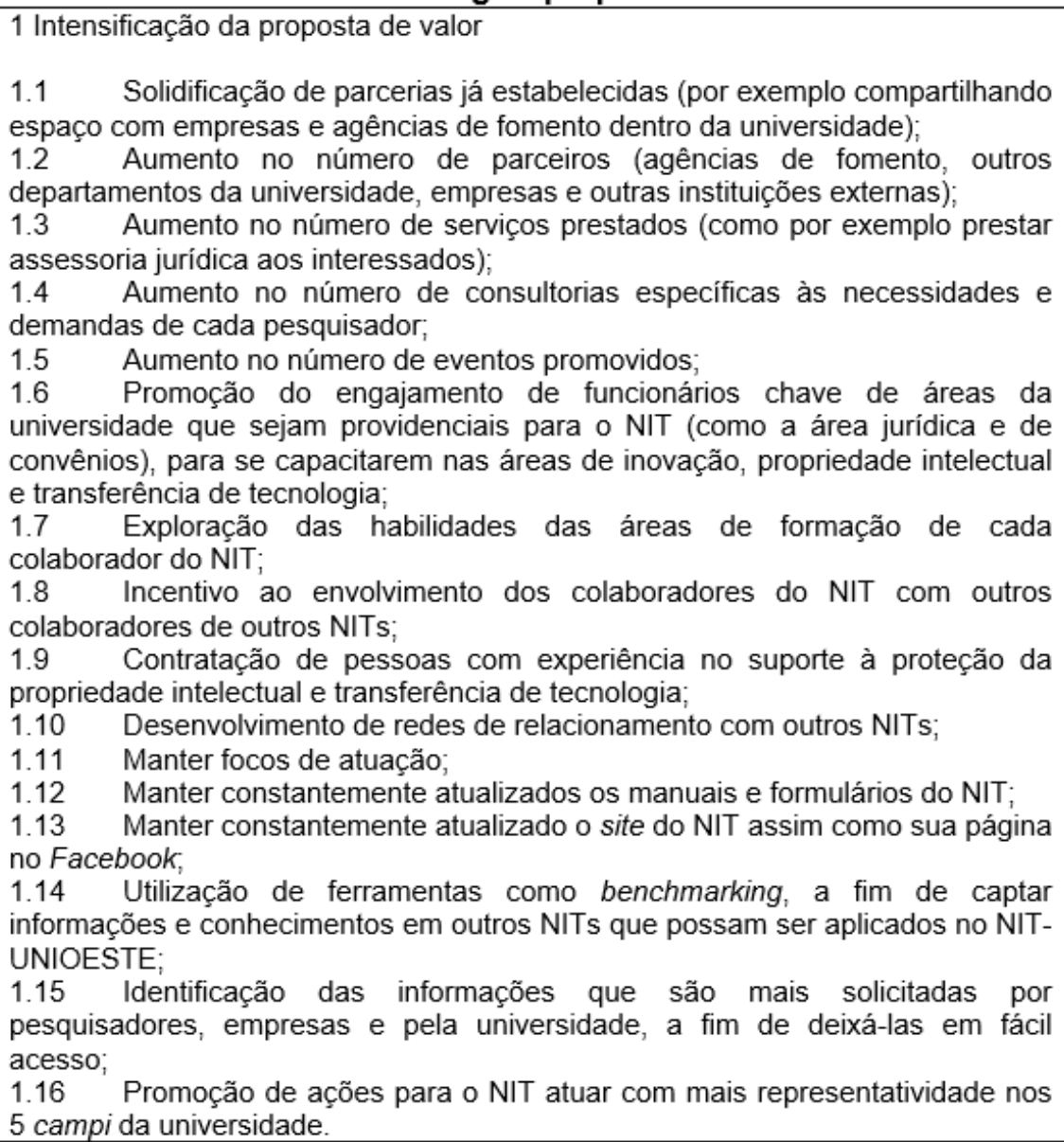 \\
\hline
\end{tabular}

Figura 4 continua na próxima página... 


\begin{tabular}{|c|c|}
\hline $\begin{array}{lr}2 & \text { Sustentabilidade das } \\
\text { atividades do departamento }\end{array}$ & $\begin{array}{l}\text { 2 Aprimoramento da gestão interna } \\
2.1 \quad \text { Promoção da difusão da missão, visão e objetivos do NIT entre os seus } \\
\text { colaboradores; } \\
2.2 \quad \text { Promoção da difusão do conhecimento sobre o regulamento do NIT, } \\
\text { sobre os regulamentos da universidade que norteiam as atividades do NIT e } \\
\text { sobre as Leis nacionais que o regem, pelos colaboradores do NIT; } \\
2.3 \quad \text { Promoção da capacitação dos colaboradores do NIT nas áreas } \\
\text { especificas em que o NIT necessita; } \\
2.4 \quad \text { Promoção da troca de conhecimentos e informações entre os } \\
\text { colaboradores do NIT (reuniões, encontros, atividades informais); } \\
2.5 \quad \text { Promoção da divisão de tarefas dentro do NIT; } \\
2.6 \quad \text { Padronização e documentação das principais atividades e processos do } \\
\text { NIT. }\end{array}$ \\
\hline $\begin{array}{lr}3 & \text { Sustentabilidade } \\
\text { financeira do departamento }\end{array}$ & $\begin{array}{l}\text { 3 Aumento da arrecadação de recursos financeiros } \\
3.1 \quad \text { Expandir a prestação de serviços de proteção à propriedade intelectual } \\
\text { para o público externo com definição de taxas para tal, por meio de submissão } \\
\text { de projeto de extensão à universidade a fim de receber autorização para tal } \\
\text { serviço; } \\
3.2 \text { Aumento no número de eventos promovidos em parceria com outros } \\
\text { departamentos da universidade; } \\
3.3 \text { Aumento no número de eventos promovidos em parceria com } \\
\text { instituições externas (universidades, empresas) } \\
3.4 \quad \text { Aumento no número de projetos enviados às agências de fomento. }\end{array}$ \\
\hline $\begin{array}{l}4 \text { Aumento do número de } \\
\text { proteçôes intelectuais da } \\
\text { UNIOESTE em quantidade } \\
\text { e qualidade }\end{array}$ & $\begin{array}{l}\text { 4 Aumento do marketing para atração da comunidade acadêmica assim como da } \\
\text { capacitação desse público } \\
4.1 \quad \text { Realizar prospecção de potenciais pesquisadores nos } 5 \text { campi da } \\
\text { universidade; } \\
4.2 \quad \text { Instituir processo para mapeamento e monitoramento de projetos de } \\
\text { pesquisa em andamento na universidade, a fim de identificar os projetos com } \\
\text { potencial inovador; } \\
4.3 \quad \text { Segmentar cursos de graduação e pós-graduação com maior potencial } \\
\text { inovador dentro da universidade; } \\
4.4 \quad \text { Realizar eventos para a conscientização sobre a importância do } \\
\text { empreendedorismo, da inovação, da proteção da propriedade intelectual e da } \\
\text { transferência de tecnologia dentro da universidade para atração de potenciais } \\
\text { pesquisadores; } \\
4.5 \quad \text { Realizar eventos para divulgar a propriedade intelectual já protegida da } \\
\text { universidade assim como o papel e as atividades do NIT dentro da universidade } \\
\text { para atração de potenciais pesquisadores; } \\
4.6 \text { Manter constantemente atualizado o site do NIT assim como sua página } \\
\text { no Facebook. }\end{array}$ \\
\hline $\begin{array}{l}5 \text { Aumento do número de } \\
\text { transferências } \\
\text { tecnologia da UNIOESTE } \\
\text { para as empresas e } \\
\text { sociedade }\end{array}$ & $\begin{array}{l}\text { 5 Aumento do marketing para atração da comunidade externa } \\
5.1 \quad \text { Manter constantemente atualizado o site do NIT assim como sua página } \\
\text { no Facebook, } \\
5.2 \text { Realizar eventos para divulgar a propriedade intelectual já protegida da } \\
\text { universidade assim como o papel e as atividades do NIT fora da universidade } \\
\text { para atração de potenciais parceiros e interessados; } \\
5.3 \quad \text { Realizar eventos para empresas específicas, de acordo com as áreas } \\
\text { da propriedade intelectual já protegida da universidade; } \\
5.4 \text { Prospecção de parcerias que sejam interessantes para as áreas de } \\
\text { pesquisa da universidade; } \\
5.5 \quad \text { Busca ativa por problemas e demandas das empresas e da sociedade, } \\
\text { a fim de identificar os projetos de pesquisa em andamento na universidade que } \\
\text { se encaixem, ou de orientar os pesquisadores da universidade quanto à direção } \\
\text { de suas novas pesquisas, e, assim, ser mais fácil a "compra" dos resultados } \\
\text { dessas pesquisas por parceiros e interessados. }\end{array}$ \\
\hline
\end{tabular}

Figura 4 - Estratégias propostas para o NIT objeto do estudo

Fonte: Elaborada pelos autores (2019) 
Posteriormente, transformou-se as algumas estratégias a serem seguidas para o alcance dos resultados de cada objetivo definido - expressas na Figura 4 - em valores quantitativos, por meio de metas, estipulando-se prazos de curto, médio e longo prazos para serem atingidas, permitindo ao departamento um melhor direcionamento de seus esforços e um melhor acompanhamento dos seus resultados. As metas para algumas das estratégias propostas estão expressas na Figura 5.

\begin{tabular}{|c|c|c|c|}
\hline Estratégias & $\begin{array}{c}\text { Metas de curto prazo } \\
\text { propostas (Até maio de } \\
2020 \text { ) }\end{array}$ & $\begin{array}{c}\text { Metas de médio prazo } \\
\text { propostas (Até maio de } \\
2022 \text { ) }\end{array}$ & $\begin{array}{c}\text { Metas de longo prazo } \\
\text { propostas (Até maio de } \\
2024 \text { ) }\end{array}$ \\
\hline 1.1 & $\begin{array}{l}\text { Compartilhar espaço dentro } \\
\text { da universidade com uma } \\
\text { instituição parceira; }\end{array}$ & $\begin{array}{l}\text { Ter compartilhado espaço } \\
\text { dentro da universidade com } \\
\text { três instituições parceiras } \\
\text { desde 2019; }\end{array}$ & $\begin{array}{l}\text { Ter compartilhado espaço } \\
\text { dentro da universidade com } \\
\text { cinco instituições parceiras } \\
\text { desde } 2019 \text {. }\end{array}$ \\
\hline 1.2 & $\begin{array}{l}\text { Captar mais um parceiro } \\
\text { para o NIT; }\end{array}$ & $\begin{array}{l}\text { Ter captado três novos } \\
\text { parceiros para o NIT desde } \\
2019 \text {; }\end{array}$ & $\begin{array}{l}\text { Ter captado cinco novos } \\
\text { parceiros para o NIT desde } \\
2019 \text {. }\end{array}$ \\
\hline 1.6 & $\begin{array}{l}\text { Conseguir a capacitação de } \\
\text { um funcionário chave da } \\
\text { universidade em alguma das } \\
\text { áreas em que o NIT } \\
\text { necessita; }\end{array}$ & $\begin{array}{l}\text { Ter conseguido a capacitação } \\
\text { de três funcionários chave da } \\
\text { universidade em alguma das } \\
\text { áreas em que o NIT necessita } \\
\text { desde } 2019 ;\end{array}$ & $\begin{array}{l}\text { Ter conseguido a capacitação } \\
\text { de cinco funcionários chave } \\
\text { da universidade em alguma } \\
\text { das áreas em que o NIT } \\
\text { necessita desde 2019. }\end{array}$ \\
\hline 1.9 & $\begin{array}{l}\text { Contratar um profissional } \\
\text { com experiência no suporte à } \\
\text { proteção da propriedade } \\
\text { intelectual e transferência de } \\
\text { tecnologia; }\end{array}$ & $\begin{array}{l}\text { Contratar um profissional com } \\
\text { experiência no suporte à } \\
\text { proteção da propriedade } \\
\text { intelectual e transferência de } \\
\text { tecnologia; }\end{array}$ & $\begin{array}{l}\text { Contratar um profissional com } \\
\text { experiência no suporte à } \\
\text { proteção da propriedade } \\
\text { intelectual e transferência de } \\
\text { tecnologia. }\end{array}$ \\
\hline 1.16 & $\begin{array}{l}\text { Promover um evento em um } \\
\text { campus da universidade; }\end{array}$ & $\begin{array}{l}\text { Ter promovido três eventos } \\
\text { em três campi diferentes da } \\
\text { universidade (um em cada } \\
\text { campus) desde 2019; }\end{array}$ & $\begin{array}{l}\text { Ter promovido cinco eventos } \\
\text { em cinco campi diferentes da } \\
\text { universidade (um em cada } \\
\text { campus) desde } 2019 \text {. }\end{array}$ \\
\hline 2.3 & 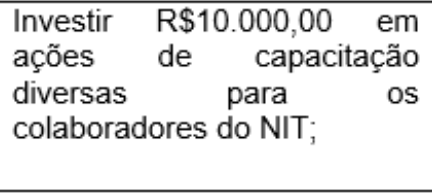 & $\begin{array}{l}\text { Ter investido R } \$ 110.000,00 \\
\text { em ações de capacitação } \\
\text { diversas parar os } \\
\text { colaboradores do NIT desde } \\
2019 ;\end{array}$ & $\begin{array}{l}\text { Ter investido R } \$ 210.000,00 \\
\text { em ações de capacitação } \\
\text { diversas para os } \\
\text { colaboradores do NIT desde } \\
2019 \text {. }\end{array}$ \\
\hline 3.1 & $\begin{array}{l}\text { Prover receita líquida de } \\
\text { R\$5.000,00 por meio da } \\
\text { expansão da prestação de } \\
\text { serviços ao público externo; }\end{array}$ & $\begin{array}{l}\text { Ter provido receita líquida de } \\
\mathrm{R} \$ 105.000,00 \text { por meio da } \\
\text { expansão da prestação de } \\
\text { serviços ao público externo } \\
\text { desde } 2019 \text {; }\end{array}$ & $\begin{array}{l}\text { Ter provido receita líquida de } \\
\mathrm{R} \$ 205.000,00 \text { por meio da } \\
\text { expansão da prestação de } \\
\text { serviços ao público externo } \\
\text { desde } 2019 \text {. }\end{array}$ \\
\hline
\end{tabular}

Figura 5 continua na próxima página... 
...continuação da Figura 5.

\begin{tabular}{|c|c|c|c|}
\hline 3.2 & $\begin{array}{l}\text { Prover receita líquida de } \\
\text { R\$20.000,00 por meio de } \\
\text { eventos promovidos em } \\
\text { parceria com outros } \\
\text { departamentos } \\
\text { universidade; }\end{array}$ & $\begin{array}{l}\text { Ter provido receita líquida de } \\
\text { R\$120.000,00 por meio de } \\
\text { eventos promovidos em } \\
\text { parceria com outros } \\
\text { departamentos } \\
\text { universidade desde 2019; da }\end{array}$ & $\begin{array}{l}\text { Ter provido receita líquida de } \\
\text { R\$220.000,00 por meio de } \\
\text { eventos promovidos em } \\
\text { parceria com outros } \\
\text { departamentos } \\
\text { universidade desde 2019. da }\end{array}$ \\
\hline 3.3 & $\begin{array}{l}\text { Prover receita líquida de } \\
\text { R } \$ 30.000,00 \text { por meio de } \\
\text { eventos promovidos em } \\
\text { parceria com instituiçôes } \\
\text { externas; }\end{array}$ & $\begin{array}{l}\text { Ter provido receita líquida de } \\
\mathrm{R} \$ 130.000,00 \text { por meio de } \\
\text { eventos promovidos em } \\
\text { parceria com instituições } \\
\text { externas desde 2019; }\end{array}$ & $\begin{array}{l}\text { Ter provido receita líquida de } \\
\text { R } \$ 230.000,00 \text { por meio de } \\
\text { eventos promovidos em } \\
\text { parceria com instituições } \\
\text { externas desde } 2019 \text {. }\end{array}$ \\
\hline 4 & $\begin{array}{l}\text { Investir R\$15.000,00 em } \\
\text { ações de marketing, } \\
\text { prospecção e capacitação } \\
\text { diversas para a comunidade } \\
\text { acadêmica da universidade; }\end{array}$ & $\begin{array}{l}\text { Ter investido R } \$ 115.000,00 \\
\text { em ações de marketing e } \\
\text { capacitação diversas para a } \\
\text { comunidade acadêmica da } \\
\text { universidade desde 2019; }\end{array}$ & $\begin{array}{l}\text { Ter investido R } \$ 215.000,00 \\
\text { em ações de marketing e } \\
\text { capacitação diversas para a } \\
\text { comunidade acadêmica da } \\
\text { universidade desde } 2019 \text {. }\end{array}$ \\
\hline 5 & $\begin{array}{l}\text { Investir } \mathrm{R} \$ 20.000,00 \mathrm{em} \\
\text { ações de marketing } \mathrm{e} \\
\text { prospecção diversas para a } \\
\text { comunidade externa; }\end{array}$ & $\begin{array}{l}\text { Ter investido } \mathrm{R} \$ 120.000,00 \\
\text { em ações de marketing e } \\
\text { prospecção diversas para a } \\
\text { comunidade externa desde } \\
2019 ;\end{array}$ & $\begin{array}{l}\text { Ter investido } \mathrm{R} \$ 220.000,00 \\
\text { em ações de marketing e } \\
\text { prospecção diversas para a } \\
\text { comunidade externa desde } \\
2019 \text {. }\end{array}$ \\
\hline
\end{tabular}

Figura 5 - Metas propostas para o NIT objeto do estudo

Fonte: Elaborada pelos autores (2019).

Depois de definidas as metas - expressas na Figura 5 - para cada estratégia proposta, por fim, delimitou-se os indicadores de desempenho para alguns dos objetivos definidos, os quais estão expressos na Figura 6.

\begin{tabular}{|c|c|c|}
\hline Objetivos & $\begin{array}{c}\text { Indicadores de } \\
\text { desempenho propostos }\end{array}$ & Cálculos dos indicadores de desempenho \\
\hline 1 & $\begin{array}{lll}\begin{array}{l}\text { Número } \\
\text { parceiros }\end{array} & \text { de novos } \\
\end{array}$ & $\begin{array}{l}\text { Número de parceiros atuais - Número de parceiros do } \\
\text { ano anterior }\end{array}$ \\
\hline 3 & $\begin{array}{l}\text { Número de prestação de } \\
\text { serviços externos }\end{array}$ & $\begin{array}{l}\text { Número total de patentes/marcas/programas de } \\
\text { computador depositados/registrados }- \text { Número de } \\
\text { patentes/marcas/programas de computador } \\
\text { depositados/registrados que contenham participação de } \\
\text { inventores da universidade }\end{array}$ \\
\hline 3 & Resultado líquido & (Saldo de caixa + Receitas totais) - Despesas totais \\
\hline 4 & $\begin{array}{l}\text { Desempenho de } \\
\text { Marketing, prospecção e } \\
\text { capacitação interna }\end{array}$ & $\begin{array}{l}\text { Valor investido em marketing, prospecção e capacitação } \\
\text { interna/Número de propostas submetidas ao NIT }\end{array}$ \\
\hline 4 & $\begin{array}{l}\text { Eficácia de Marketing, } \\
\text { prospeç̧ão e capacitação } \\
\text { interna }\end{array}$ & $\begin{array}{l}\text { Número de propostas submetidas ao NIT/Número de } \\
\text { proteções intelectuais }\end{array}$ \\
\hline 5 & $\begin{array}{l}\text { Desempenho } \mathrm{de} \\
\text { Marketing e prospecção } \\
\text { externa }\end{array}$ & $\begin{array}{l}\text { Valor investido em marketing e e prospecção } \\
\text { externa/Número de propostas submetidas ao NIT }\end{array}$ \\
\hline 5 & $\begin{array}{l}\text { Eficácia de Marketing e } \\
\text { prospecção externa }\end{array}$ & $\begin{array}{l}\text { Número de propostas submetidas ao NIT/Número de } \\
\text { transferências de tecnologia }\end{array}$ \\
\hline
\end{tabular}

Figura 6 - Indicadores de desempenho propostos para o NIT objeto do estudo Fonte: Elaborada pelos autores (2019). 
Os indicadores de desempenho expressos na Figura 6 têm o objetivo de permitir maior controle do desenvolvimento das ações estratégicas do departamento, fechando, então, o planejamento proposto.

\section{Considerações Finais}

Este trabalho teve como objetivo analisar o atual cenário e propor um planejamento estratégico para o Núcleo de Inovação Tecnológica (NIT) da Universidade Estadual do Oeste do Paraná (UNIOESTE), com vistas a aprimorar a gestão interna do mesmo. Com base no levantamento de estudos sobre o contexto dos NITs, na pesquisa em documentos internos e na observação participante no NIT objeto de estudo e, ainda, nas reuniões e entrevistas com o gestor e demais colaboradores do departamento, analisando variáveis que interferem no seu desempenho, foi determinado e analisado o estado atual do NIT, com a aplicação das ferramentas estratégicas Canvas e análise SWOT, e, assim, foi possível determinar e propor o estado no qual o NIT quer chegar, por meio da definição da missão, da visão e dos objetivos do NIT, e, por fim, por meio das estratégias, metas e indicadores de desempenho que foram propostos para o departamento com o objetivo de minimizar seus pontos fracos e suas ameaças e potencializar seus pontos fortes e suas oportunidades.

O resultado da intervenção, foi, então, um instrumento documentado e formalizado de planejamento estratégico, contemplando direção e controle, para o NIT. Para esse instrumento foram elaborados o Canvas e a análise SWOT do departamento assim como definidas sua missão, visão e objetivos, ferramentas que, uma vez documentadas, servem como instrumentos de gestão e podem ser constantemente aprimoradas conforme necessidade.

Como contribuição ao NIT, têm-se a posse de um instrumento de planejamento e monitoramento para subsidiar suas atividades e, assim, a possibilidade do departamento avançar na sua organização e desempenho, de forma eficiente e sustentável, considerando, principalmente, a dificuldade do departamento em dar continuidade nas suas ações, principalmente pelo fato de quase todos os colaboradores serem temporários, e, ainda, visto a falta de mecanismos de direção e controle no departamento.

Além do NIT objeto da pesquisa, ressalta-se que o resultado deste estudo pode servir como base e ser adaptado em outros NITs nacionais e internacionais, visto as dificuldades semelhantes enfrentadas por estes departamentos. 
Como sugestão para estudos futuros, recomenda-se o acompanhamento da implementação das ferramentas estratégicas no NIT e do desenvolvimento das estratégias e metas pelo departamento, observando seu progresso por meio dos indicadores de desempenho propostos, propondo adaptações que enriqueçam essas ferramentas, principalmente na situação de uma possível mudança de gestão e equipe.

Sugere-se a elaboração de projeções financeiras incluindo as despesas do NIT juntamente às possibilidades de incremento da receita propiciado pelas estratégias e metas enunciadas, para assim, somando os valores das receitas provenientes das estratégias e metas propostas e as despesas projetadas, ser possível projetar de fato a sustentabilidade financeira do departamento para alcance em cinco anos, estágio em que ele não precise mais de recursos da universidade em que está inserido e seja capaz de se manter sozinho, já que neste estudo não foi possível essa elaboração e o aprofundamento neste objetivo devido à falta de informações das fontes de entradas e saídas de caixa do NIT, pelo fato do departamento não ter esse controle atualmente e do seu coordenador estar buscando no momento essas informações junto ao setor financeiro da universidade em que o NIT está inserido, já que há muitas informações desencontradas principalmente do que está entrando no caixa do NIT, que precisam ser verificadas, além de junto ao financeiro da universidade, às empresas que já possuem parceria com o NIT com contratos de transferência de tecnologia. Com as projeções financeiras, recomenda-se aprimorar as metas enunciadas em planejamento.

É importante a expansão da pesquisa junto aos segmentos de clientes do NIT definidos em seu Canvas, a fim de constatar a realidade por eles vivenciada em relação ao NIT para validar e complementar as informações coletadas.

\section{Referências}

Almeida, M. L., Silva, J. L. G., \& Oliveira, E. A. A. Q. (2014). A inovação como fator de desenvolvimento regional. Revista Brasileira de Gestão e Desenvolvimento Regional, 10(3), 314-350.

Alves, V.C., Segundo, G. S. A., \& Sampaio, R. R. (2015). Reflexões sobre as competências dos núcleos de inovação tecnológica. Cadernos de Prospecção, 8(4), 688-696.

Bakouros, Y. L., \& Samara, E. T. (2010). Academic liaison offices vs. technology transfer units: Could they form a new joint mechanism towards the exploration of academic/research results?. International Journal of Innovation Science, 2(4), 145-157.

Beltrán, P. A., Bautista, R. P., \& Sáez, F. J. (2017). An in-depth analysis of a TTO's objectives alignment within the university strategy: An ANP-based approach. Journal of Engineering and Technology Management, 44, 19-43. 
Bortolini, H. V., Cário, S. A. F., Constante, J. M., \& Lemos, D. C. (2014). Análise da implementação e operação dos núcleos de inovação tecnológica (NITs) no Brasil: Estrutura, gestão e relação com o setor produtivo. Anais do VIII Encontro de Estudos em Empreendedorismo e Gestão de Pequenas Empresas (EGEPE). Goiânia-GO.

Bueno, A. \& Torkimian, A. L. V. (2018). Índices de licenciamento e de comercialização de tecnologias para núcleos de inovação tecnológica baseados em boas práticas internacionais. Revista eletrônica de biblioteconomia e ciência da informação, 23(51), 95-107.

Chiavenato, I., \& Sapiro, A. (2003). Planejamento estratégico. Rio de Janeiro: Elsevier.

Coelho, L. C. D., \& Dias, A. A. (2016). O núcleo de inovação tecnológica da UFPE: Instrumento de política de inovação ou obrigação legal?. Revista de Administração, Contabilidade e Economia da Fundace, 7(1), 28-42.

Costa, C. O. M. (2013). Transferência de tecnologia universidade-indústria no Brasil e a atuação de núcleos de inovação tecnológica. Dissertação de Mestrado, Escola Politécnica, Universidade de São Paulo, São Paulo.

Costa, P. R., \& Junior, S. S. B. (2016). Atuação dos núcleos de inovação tecnológica na gestão da cooperação universidade-empresa. Revista de Administração FACES Journal, 15(4), 25-45.

Desidério, P. H. M., \& Zilber, M. A. (2014). Barreiras no processo de transferência tecnológica entre agências de inovação e empresas: Observações em universidades públicas e privadas. Revista Gestão \& Tecnologia, 14(2), 101-126.

Dyson, R. G. (2004). Strategic development and SWOT analysis at the University of Warwick. European journal of operational research, 152, 631-640.

Figueiredo, P. N. (2005). Acumulação tecnológica e inovação industrial: Conceitos, mensuração e evidências no Brasil. São Paulo em perspectiva, 19(1), 54-69.

Fujino, A., \& Stal, E. (2007). Gestão da propriedade intelectual na universidade pública brasileira: Diretrizes para licenciamento e comercialização. Revista de Negócios, 12(1), 104-120.

Garcia, D. L., Bisneto, J. P. M., \& Santos, E. M. (2017). Núcleo de inovação tecnológica da Universidade Federal do Recôncavo da Bahia: Um diagnóstico setorial. Revista Brasileira de Gestão e Inovação, 5(1), 23-49.

Gumbi, S. (2010). A review of performance standards to monitor, evaluate and assess the impact of technology transfer offices. South African Journal of Science, 106(7-8), 1-9.

Iata, C. M., Teixeira, C. S., Macedo, M., \& Cunha, C. J. C. A. (2017). O perfil e as práticas de interação dos núcleos de inovação tecnológica de Santa Catarina pela abordagem da tríplice hélice. Espacios, 38(11), 1-14.

Katz, I. S. S., Prado, F. O., \& Souza, M. A. (2018). Processo de implantação e estruturação do núcleo de inovação tecnológica. Revista Gestão \& Tecnologia, 18(1), 225-251.

Lata, C., \& Cunha, C. J. C. A. (2018). A atuação da tríplice hélice em Santa Catarina pela visão dos núcleos de inovação tecnológica (NITs) do Estado. Navus: Revista de Gestão e Tecnologia, 8(4), 180-188.

Lei ${ }^{\circ} 10.973$, de 2 de dezembro de 2004. Dispõe sobre incentivos à inovação e à pesquisa científica e tecnológica no ambiente produtivo e dá outras providências. http://www.planalto.gov.br/ccivil_03/_ato2004-2006/2004/lei/110.973.htm

Machado, H. P. V., Sartori, R., \& Crubellate, J. M. (2017). Institucionalização de núcleos de inovação tecnológica em instituições de ciência e tecnologia da região Sul do Brasil. Revista Eletrônica de Administração, 23(3), 5-31. 
Marin, A., Hadãr, A., Purcãrea, A. A., \& Boantã, L. (2017). Business modeling process for university's technology transfer offices. De Gruyter, 1033-1049.

Mikosz, V. M., \& Lima, I. A. (2018). A relação universidade-empresa-governo: Mecanismos de cooperação e seus fatores intervenientes em uma universidade pública. Revista Tecnologia e Sociedade, 14(34), 215-239.

Núcleo de Inovações Tecnológicas - NIT UNIOESTE (2019). https://www5.unioeste.br/portal/nucleos/nit

O’kane, C., Mangematin, V., Geoghegan, W., \& Fitzgerald, C. (2015). University technology transfer offices: The search for identity to build legitimacy. Research Policy, 44, 421-437.

Osterwalder, A., \& Pigneur, Y. (2011). Business Model Generation - Inovação em Modelos de Negócios: um manual para visionários, inovadores e revolucionários. Rio de Janeiro: Alta Books.

Paranhos, J., Cataldo, B., \& Pinto, A. C. A. (2018). Criação, institucionalização e funcionamento dos núcleos de inovação tecnológica no Brasil: Características e desafios. Revista Eletrônica de Administração, 24(2), 253-280.

Pereira, M. F., Melo, P. A., Dalmau, M. B., \& Harger, C. A. (2009). Transferência de conhecimentos científicos e tecnológicos da universidade para o segmento empresarial. Revista de Administração e Inovação, 6(3), 128-144.

Pereira, R. P. A., Melo, D. R. A., \& Júnior, D. C. V. (2017). Nível de maturidade de um NIT: Estudo de caso na pró reitoria de inovação tecnológica da Universidade Federal do Amazonas. Anais do V Simpósio de Engenharia de Produção - SIMEP.

Pietrovski, E. F. (2017). Ações de gestão para apoiar os núcleos de inovação tecnológica nas instituições de ensino superior. Tese de Doutorado, Programa de Mestrado e Doutorado em Administração, Universidade Positivo, Curitiba.

Pires, E. A., \& Quintella, C. M. A. T. (2015). Política de propriedade intelectual e transferência de tecnologia nas universidades: Uma perspectiva do NIT da Universidade Federal do Recôncavo da Bahia. Holos, 31(6), 178-195.

Queiroz, D. C., \& Meza, M. L. F. G. (2018). Produção de ciência e tecnologia dos inventores de uma universidade tecnológica: Insights sobre a presença da ecoinovação na tecnologia. Revista Tecnologia e Sociedade, 14(34), 240-260.

Rennó, A. S., Zambalde, A. L., Veroneze, R. B., \& Sousa, D. (2016). Appropriation mechanisms of search results: A case study in a public university of Minas Gerais. Revista de Administração e Inovação, 13, 274-284.

Rosa, R. A., \& Frega, J. R. (2017). Intervenientes do processo de transferência tecnológica em uma universidade pública. Revista de Administração Contemporânea, 21(4), 435457.

Santos, A. L., \& Silva, S. C. (2017). Desenvolvimento de um modelo de gestão do conhecimento em um núcleo de inovação tecnológica. Revista Eletrônica Sistemas \& Gestão, 12(1), 1-13.

Sartori, R., Spinosa, L. M., \& Nogas, P. S. M. (2017). Práticas de gestão em um núcleo de inovação tecnológica: O caso da Universidade Estadual de Maringá. Revista Eletrônica Sistemas \& Gestão, 12(3), 377-390.

Sengupta, A., \& Ray, A. S. (2017). Choice of structure, business model and portfolio: Organizational models of knowledge transfer offices in british universities. British Journal of Management, 28, 687-710.

Sharifi, H., Liu, W., \& Ismail, H. S. (2014). Higher education system and the 'open' knowledge transfer: A view from perception of senior managers at university knowledge transfer offices. Studies in Higher Education, 39(10), 1860-1884. 
Silva, A. S. B., \& Silva, R. P. (2015). Inovação, propriedade intelectual e os núcleos de inovação tecnológica (NIT). Anais do IV SINGEP. São Paulo-SP.

Silva, L. C. S., Kovaleski, J. L., \& Gaia, S. (2013). Gestão do conhecimento organizacional visando à transferência de tecnologia: Os desafios enfrentados pelo NIT da Universidade Estadual de Santa Cruz. Revista Produção Online, 13(2), 677-702.

Silva, L. C. S., Kovaleski, J. L., Gaia, S., Segundo, G. S. A, \& Caten, C. S. T. (2015). Processo de transferência de tecnologia em universidades públicas brasileiras por intermédio dos núcleos de inovação tecnológica. Interciencia, 40(10), 664-669.

Silva, L. R. (2015). Estudo sobre os padrões de organização e práticas de gestão em núcleo de inovação tecnológica nas universidades: Análise multicaso entre instituições públicas e privadas. Dissertação de Mestrado, Programa de Pós-Graduação em Administração, Centro Universitário da FEI, São Paulo.

Silva, L. R., Bernardes, R. C., \& Gattaz, C. C. (2015). Um comparativo das estratégias tecnológicas e de negócios na gestão dos NITs brasileiros em universidades públicas e privadas. Anais do XVI Congresso Latino-Iberoamericano de Gestão da Tecnologia. Porto Alegre-RS.

Souza, A. C. M. M. (2011). Gestão de núcleos de inovação tecnológica. Anais do XI Colóquio Internacional sobre Gestão Universitária na América do Sul e II Congresso Internacional IGLU. Florianópolis-SC.

Teixeira, L.A. C. (2018). Como os núcleos de inovação tecnológica dos institutos públicos de pesquisa podem contribuir para os resultados de inovação do Estado de São Paulo: um estudo de caso dos institutos de administração direta do governo do Estado. Tese de Doutorado, Departamento de Administração, Universidade de São Paulo, São Paulo.

Ustundag, A., Ugurlu, S., \& Kilinc, M. S. (2011). Evaluating the performance of technology transfer offices. Journal of Enterprise Information Management, 24(4), 322-337.

Weckowska, D. M. (2015). Learning in university technology transfer offices: Transactionsfocused and relations-focused approaches to commercialization of academic research. Technovation, 62-74.

Yin, R. K. (2015). Estudo de caso: Planejamento e métodos. 5. ed. Porto Alegre/Rio Grande do Sul: Bookman.

Zandavalli, C., Santos, D., Mello, M. I. C., Pichetti, R. F., Teixeira, C. S., \& Macedo, M. (2016). A inovação na perspectiva de uma instituição de ciência e tecnologia: Um olhar sobre o núcleo de inovação tecnológica. Espacios, 37(35), 1-17. 